\title{
Propeller-Like Chirality of Methyl-Tris (2,6-diisopropylphenoxy)Silylsulfide
}

\author{
Aleksander Herman • Sylwia Godlewska • \\ Lukasz Ponikiewski • Tomasz Kruczyński • \\ Anna Dołega
}

Received: 18 December 2013 / Accepted: 27 May 2014 / Published online: 14 January 2015

(C) Springer Science+Business Media Dordrecht 2015

\begin{abstract}
Two new methylsilylsulfides are synthesized. Propeller-like chirality is described for triaryloxysilanethiol and its methyl derivative. S-methylation of the silanethiol lowers the overall symmetry of the unit cell.
\end{abstract}

Keywords Silyl sulfide $\cdot$ Chirality

\section{Introduction}

A chiral compound is not superimposable on its mirror image. This criterion requires the presence of an asymmetric center or other elements within the molecule giving rise to isomerism. Compounds that lack asymmetric atoms may possess axial, planar or helical (propeller-like) chirality. Molecules with a helical shape are described as right-handed $(\mathrm{P})$ if they resemble a screw that rotates clockwise away from the viewer, or left-handed $(\mathrm{M})$ if the rotation is opposite [1].

In solid state triorganoxysilanethiols exhibit propeller type chirality. In the case of these compounds the helical character is imposed by the conformation of the organoxy substituents attached to the silicon atom: the substituents are bent in the same direction with the same sign of the torsion angle S-Si-O-C. The phenomenon was

\footnotetext{
A. Herman · S. Godlewska $\cdot$ Ł. Ponikiewski ·

T. Kruczyński · A. Dołega $(\bowtie)$

Department of Inorganic Chemistry, Gdansk University, of Technology, Narutowicza St. 11/12 80-952 Gdańsk, Poland

e-mail: anndoleg@pg.gda.pl
}

T. Kruczyński

Institute of Inorganic Chemistry, Karlsruhe Institute

of Technology, Engesserstrasse 15, Bldg. 30.45,

76128 Karlsruhe, Germany observed and described by Chojnacki for solid tri-tertbutoxysilanethiolato complexes [2,3]. In this contribution we describe a similar type of propeller chirality in aromatic analogue of tri-tert-butoxysilanethiol obtained more recently, tris(2,6-diisopropylphenoxy)silanethiol TDST [4] and its methyl derivative. With the intention of studying the methylation of silanethiols alone and within their metal complexes we have methylated two silanethiols in the form of sodium salts with methyl iodide. Out of the two obtained derivatives: methyl-tri(tert-butoxysilyl)sulphide and methyl-tris(2,6-diisopropylphenoxysilyl)sulfide the latter one was solid and its crystal structure is presented in this work.

\section{Experimental}

\subsection{General Methods}

Sodium silanethiolates were obtained as described before $[2,4]$. Methyl iodide (Sigma-Aldrich) was used as purchased. Hexane was dried over $\mathrm{Na} /$ benzophenone and distilled prior to use. The density of methyl tri-tertbutoxysilylsulfide was measured with Anton Paar DMA 5000. NMR measurements were performed at $298.5 \mathrm{~K}$ either in $\mathrm{CDCl}_{3}$ with Varian Unity Plus $500 \mathrm{MHz}$ spectrometer $\left({ }^{1} \mathrm{H},{ }^{13} \mathrm{C}\right)$ or in $\mathrm{C}_{6} \mathrm{D}_{6}$ on a Bruker AV $300 \mathrm{MHz}$ spectrometer $\left({ }^{1} \mathrm{H},{ }^{13} \mathrm{C},{ }^{29} \mathrm{Si}\right)$. The chemical shifts were related to the TMS. Elemental analyses were performed on an Elemental Analyser EA 1108 (Carlo Erba Instruments).

\subsection{Syntheses}

Methyl tris(2,6-diisopropylphenoxysilyl)sulfide (1) Sodium tris(2,6-diisopropylphenoxysilyl)sulfide $(1 \mathrm{mmol})$ was 
suspended in $25 \mathrm{ml}$ of $\mathrm{n}$-hexane. Methyl iodide solution ( $2 \mathrm{mmol}$ in $10 \mathrm{ml}$ of $\mathrm{n}$-hexane) was added drop-wise to this suspension and the reaction mixture was boiled for 4 hours. NaI precipitate that formed as a result of the reaction was removed by filtration. Colourless crystals of $\mathbf{1}$ were obtained from the filtrate placed at $-18{ }^{\circ} \mathrm{C}$ with the $20 \%$ yield (the remaining solution was not elaborated). M.p. 121.5-123.5 ${ }^{\circ} \mathrm{C}$.

${ }^{1} \mathrm{H}$ NMR $(500 \mathrm{MHz})$ in $\mathrm{CDCl}_{3}: \delta 1.09(\mathrm{~d}, 36 \mathrm{H}), 1.91$ (s, 3H), 3.39 (sept. 6H), $7.02(\mathrm{~m}, 3 \mathrm{H}), 7.06(\mathrm{~m}, 6 \mathrm{H})$ ppm; ${ }^{13} \mathrm{C}$ NMR $(125 \mathrm{MHz})$ in $\mathrm{CDCl}_{3}: \delta 8.7\left(\mathrm{SCH}_{3}\right)$, $23.9\left(\mathrm{CH}\left(\mathrm{CH}_{3}\right)_{2}\right), 27.5\left(\mathrm{CH}\left(\mathrm{CH}_{3}\right)_{2}\right), 123.6$ (aromatic ring 4-C), 124,0 (aromatic ring 3,5-C), 139.3 (aromatic ring 2,6-C), 148.1 (aromatic ring $C-\mathrm{O}-\mathrm{Si}$ ) ppm.

${ }^{1} \mathrm{H}$ NMR $(300 \mathrm{MHz})$ in $\mathrm{C}_{6} \mathrm{D}_{6}: \delta 1.17(\mathrm{~d}, 36 \mathrm{H}), 1.72$ (s, 3H), 3.61 (sept. 6H), $7.0(\mathrm{~m}, 9 \mathrm{H}) \mathrm{ppm} ;{ }^{13} \mathrm{C} \mathrm{NMR}$ $(75 \mathrm{MHz})$ in $\mathrm{C}_{6} \mathrm{D}_{6}: \delta 8.0\left(\mathrm{SCH}_{3}\right), 23.6\left(\mathrm{CH}\left(\mathrm{CH}_{3}\right)_{2}\right)$, $27.3\left(\mathrm{CH}\left(\mathrm{CH}_{3}\right)_{2}\right), 123.7$ (aromatic ring $\left.4-\mathrm{C}\right), 123,8$ (aromatic ring 3,5-C), 139.1 (aromatic ring 2,6-C), 148.0 (aromatic ring $C$-O-Si) ppm. ${ }^{29} \mathrm{Si} \mathrm{NMR}(59.6 \mathrm{MHz}$ ) in $\mathrm{C}_{6} \mathrm{D}_{6}: \delta-73.1\left(\mathrm{q},{ }^{3} J_{\mathrm{Si}-\mathrm{H}}=5.8 \mathrm{~Hz}, \mathrm{SiSCH}_{3}\right)$ ppm.

Methyl tri-tert-butoxysilylsulfide (2) Sodium tri-tert-butoxysilanethiolate $(30 \mathrm{mmol})$ was dissolved in $100 \mathrm{ml}$ of boiling $n$-hexane. Methyl iodide solution $(75 \mathrm{mmol}$ in $30 \mathrm{ml}$ of $\mathrm{n}$-hexane) was added drop-wise to this solution and the reaction mixture was boiled for approximately 24 hours. During this period the precipitation of initially white and then greyish precipitate was observed. After 24 hours the greyish precipitate of $\mathrm{NaI}$ was filtered and the obtained solution was distilled under reduced pressure. Fraction boiling at $45^{\circ} \mathrm{C}(1 \mathrm{mmHg})$ contained the product 2 . The yield of the distilled product was $35 \% . d^{20{ }^{\circ} \mathrm{C}}=0.921691 \pm 0.00005 \mathrm{~g} / \mathrm{cm}^{3}$. Anal calcd. C-53.01, H-10.27, S-10.89, anal. found: C-52.92, H-10.27, S-10.89.

${ }^{1} \mathrm{H}$ NMR $(500 \mathrm{MHz})$ in $\mathrm{CDCl}_{3}: \delta 1.35(\mathrm{~s}, 27 \mathrm{H})$, $2.04(\mathrm{~s}, 3 \mathrm{H}) \mathrm{ppm} ;{ }^{13} \mathrm{C} \mathrm{NMR}(125 \mathrm{MHz})$ in $\mathrm{CDCl}_{3}$ : $\delta 9.7\left(\mathrm{SCH}_{3}\right), \quad 31.6\left(\mathrm{OC}\left(\mathrm{CH}_{3}\right)_{3}\right), 74.1 \quad\left(\mathrm{OC}^{2}\left(\mathrm{CH}_{3}\right)_{3}\right)$ ppm.

${ }^{1} \mathrm{H}$ NMR $(300 \mathrm{MHz})$ in $\mathrm{C}_{6} \mathrm{D}_{6}: \delta 1.29(\mathrm{~s}, 27 \mathrm{H}), 1.94$ (s, 3H) ppm; ${ }^{13} \mathrm{C}$ NMR $(75 \mathrm{MHz})$ in $\mathrm{C}_{6} \mathrm{D}_{6}: \delta 9.04$

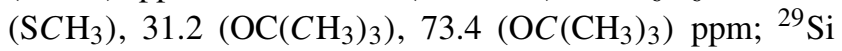
$\operatorname{NMR}(59.6 \mathrm{MHz})$ in $\mathrm{C}_{6} \mathrm{D}_{6}: \delta-70.5\left(\mathrm{q},{ }^{3} J_{\mathrm{Si}-\mathrm{H}}=5.3 \mathrm{~Hz}\right.$, $\left.\mathrm{SiSCH}_{3}\right) \mathrm{ppm}$.

\subsection{X-ray Crystal Structures Analysis}

The single crystals of $\mathbf{1}$ were used for data collection at $298(2) \mathrm{K}$ on a four-circle Oxford Diffraction Xcalibur diffractometer equipped with a two-dimensional CCD detector with graphite monochromatised Mo $\mathrm{K} \alpha$ radiation $(\lambda=0.71073 \AA)$ and the $\omega$-scan technique. Integration of the intensities and correction for Lorenz and polarisation effects were performed using CrysAlis RED software (Oxford Diffraction, 2008).

Structure of $\mathbf{1}$ was solved by direct methods and all non-hydrogen atoms were refined with anisotropic thermal parameters by full-matrix least squares procedure based on $\mathrm{F}^{2}$. Hydrogen atoms were refined using isotropic model with $\mathrm{U}_{\text {iso }}(\mathrm{H})$ values fixed to be 1.5 times $\mathrm{U}_{\text {eq }}$ of $\mathrm{C}$ atoms for $-\mathrm{CH}_{3}$ or 1.2 times $\mathrm{U}_{\mathrm{eq}}$ for $-\mathrm{CH}$ groups. Crystal structures were solved and refined using the SHELX-97 program package [5]. A summary of the crystallographic data is listed in Table 1.

Table 1 Summary of crystallo-graphic data and structure refinement details for 1

\begin{tabular}{|c|c|}
\hline Empirical formula & $\mathrm{C}_{37} \mathrm{H}_{54} \mathrm{O}_{3} \mathrm{SSi}$ \\
\hline$M_{\mathrm{r}} / \mathrm{g} \mathrm{mol}^{-1}$ & 606.95 \\
\hline Temperature /K & $298(2)$ \\
\hline Wavelength $/ \AA$ & $0.71073\left(\mathrm{Mo} \mathrm{K}_{\alpha}\right)$ \\
\hline Crystal system & Triclinic \\
\hline Space group & $P-1$ \\
\hline$a / \AA$ & $10.5938(5)$ \\
\hline$b / \AA$ & $10.5046(6)$ \\
\hline$c / \AA$ & $18.6216(19)$ \\
\hline$\alpha /^{\mathrm{o}}$ & $98.247(7)$ \\
\hline$\beta /^{\mathrm{o}}$ & $100.957(7)$ \\
\hline$\gamma /{ }^{\circ}$ & $113.710(5)$ \\
\hline$V / \AA^{3}$ & $1806.2(2)$ \\
\hline $\mathrm{Z}$ & 2 \\
\hline Calculated density $/ \mathrm{Mg} \mathrm{m}^{-3}$ & 1.116 \\
\hline Crystal size / mm & $0.17 \times 0.15 \times 0.14$ \\
\hline$\theta$ range $/^{\circ}$ & 2.16 to 28.63 \\
\hline Limiting indices & $\begin{array}{l}-13<=\mathrm{h}<=13 \\
-12<=\mathrm{k}<=12 \\
-20<=1<=20\end{array}$ \\
\hline Reflections collected / unique & $\begin{array}{l}9021 / 6319 \\
{[R \text { (int) }=0.0437]}\end{array}$ \\
\hline Completeness to $\theta_{\max } 1 \%$ & 98.0 \\
\hline Linear absorption coeff. $/ \mathrm{mm}^{-1}$ & 0.155 \\
\hline Data / restraints / parameters & $6319 / 3 / 784$ \\
\hline Goodness-of-fit on $F^{2}$ & 0.950 \\
\hline Final $R$ indices $[I>2 \sigma(I)]$ & $\begin{array}{l}R 1=0.0637 \\
w R 2=0.1522\end{array}$ \\
\hline$R$ indices (all data) & $\begin{array}{l}R 1=0.0840 \\
w R 2=0.1626\end{array}$ \\
\hline Largest diff. peak and hole $/ \mathrm{e} \AA^{-3}$ & 0.631 and -0.398 \\
\hline
\end{tabular}




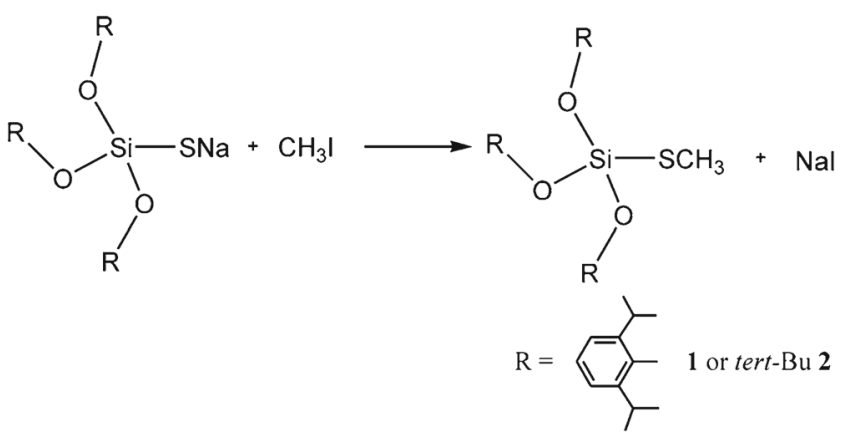

Scheme 1

\subsection{Quantum-Mechanical Calculations}

The structures of $\mathbf{1}$, TDST, TC1, TC2 were optimized with the use of ADF implemented functionals using ADF release 2013.01 of theoretical chemistry package developed at Vrije Universiteit, Amsterdam, The Netherlands [6-8]. The starting geometries were taken either from experimental crystallographic data obtained in this work or in [4] or from RM1 calculations (TC1, TC2). The GGA BLYPD XC potential in SCF and final energy evaluation with Becke integration scheme at TZP Slater basis set with large frozen core constrains were used. Delocalized coordinates were used for structure optimization. The energies of transition states TS1, TS2, TS3 were calculated at semiempirical RM1 level [9], with the use of the eigenvector following EF method described by Baker [10]. First an initial guess of the probable conformation of the transition state structure was made. The gradient vector $\mathbf{g}$ and the Hessian matrix $\boldsymbol{H}$ at the initial point was then calculated by RM1 method. The second step involved the diagonalization of the Hessian and determination of the local hypersurface characteristics, i.e., the number of negative eigenvalues. Then $\mathbf{g}$ was transformed into the local Hessian modes $\boldsymbol{F}=\mathrm{Ug}$. The next step depended on the structure of the Hessian. If the Hessian had the wrong number of negative eigenvalues (more than one) then the next step involved separation of positive and negative Hessian eigenvalues into two matrix equations. For details please refer to [10]. Our calculations were stopped at the RMS gradient lower than $0.01 \mathrm{kcal} / \AA ̊$ mol, assuming that the position of the transition state was found. If convergence criterion was not satisfied, the energy and gradient vector at the new point were calculated, provided that maximum number of steps (1440 cycles) was not reached.

\section{Results and Discussion}

Two silanethiols: tris(2,6-diisopropylphenoxy)silanethiol TDST and tri-tert-butoxysilanethiol TBST were converted into their S-methyl derivatives by the reaction of their sodium salts with methyl iodide in boiling $n$-hexane (Scheme 1). TDST is solid in the ambient temperature and
Fig. 1 The molecular structure of $\mathbf{1}$. The shortest contacts $\mathrm{CH}-\mathrm{C}$ within the molecule are marked with the dashed lines: C37-H37a-C25 3.064(7) A, $\mathrm{C} 37-\mathrm{H} 37 \mathrm{~b}-\mathrm{C} 302.943(7) \AA$, C37-H37b-C34 2.964(8) A

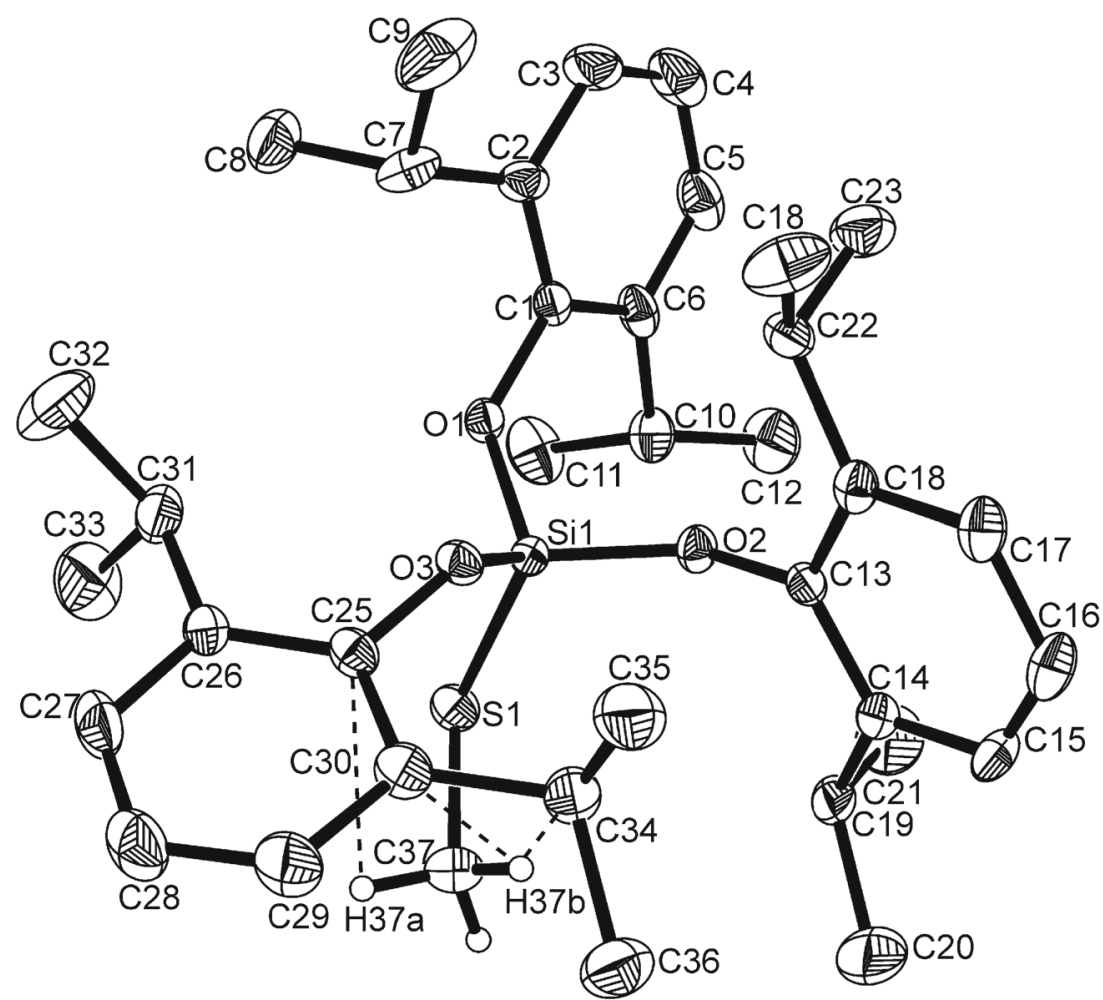


Fig. 2 Two different views of the molecule of TDST with the reference plane defined by $\mathrm{C} 1$, $\mathrm{C} 13, \mathrm{C} 25$. The torsion angles referred to in the text are [deg]: S1-Si1-O1-C1 -0.68(15),

S1-Si1-O2-C13 S1 Si1 O2 C13 -96.71(16), S1-Si1-O3-C25 $-139.23(12)$. The angles between the reference plane and the planes of aromatic rings are [deg]: (C1-C6) 5.95, (C25-C30) 67.49, (C13-C18) 84.81
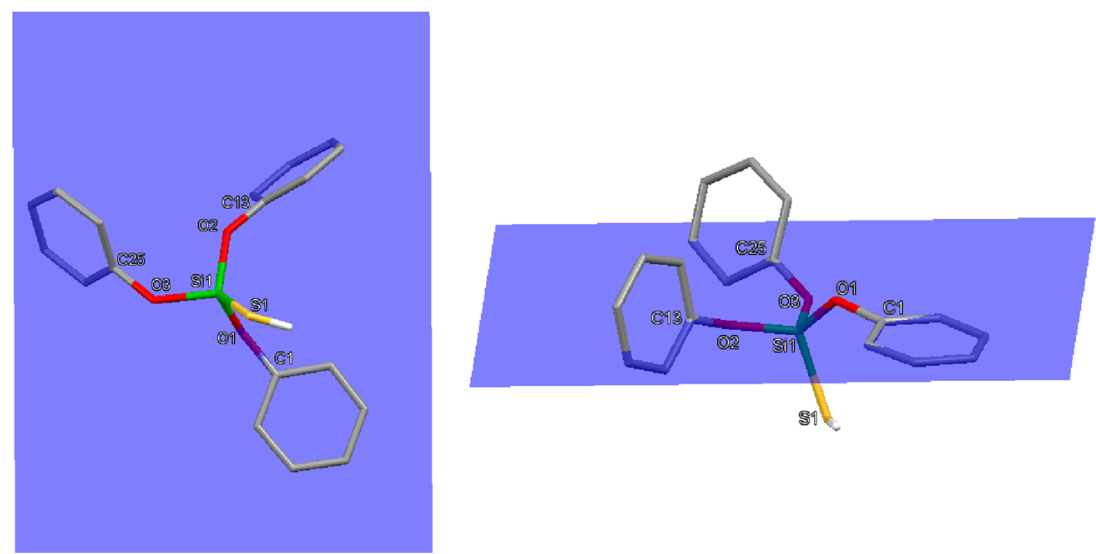

its S-methyl derivative $\mathbf{1}$ is likewise colourless crystalline solid. TBST is non-volatile liquid with the melting point $20{ }^{\circ} \mathrm{C}$ and the boiling point $115{ }^{\circ} \mathrm{C}(35 \mathrm{mmHg})$ [11]. The obtained methyl derivative 2 is also liquid with the boiling point $45^{\circ} \mathrm{C}(1 \mathrm{mmHg})$.

Molecular structure of $\mathbf{1}$, shown in Fig. 1 shows distorted tetrahedral coordination of the silicon center. The angles around the silicon are in the range. 101.97(14) $115.43(16) \mathrm{deg}$. The S-methyl group interacts with one of the phenyl rings as indicated by short intramolecular contacts: $\mathrm{CH}-\mathrm{C}$ shown in Fig. 2 and listed in Fig. 1 caption. The data on the important bond lengths and angles are gathered in Table 2.

Two aryloxysilanethiols of known crystal structure: tris(mesityloxy)silanethiol [12] and tris(2,6-diisopropylphenoxy)silanethiol [4] crystallize as solid state 50-50 racemic mixtures of two enantiomers. After Chojnacki [2] the enantiomers will be called $P$ (all torsion angles $\mathrm{S}-\mathrm{Si}-\mathrm{O}-\mathrm{C}$ positive) and $\mathrm{M}$ (the same torsion angles negative). Apart from the sign of the appropriate torsion angle, these aromatic derivatives possess an additional element of helicity introduced by the twist of the aromatic rings with regard to the reference plane (compare [13,

Table 2 Selected bond lengths and angles in 1

\begin{tabular}{llll}
\hline Bond & Length $[\AA]$ & Bond & Length $[\AA ̊$ \\
\hline S1 Si1 & $2.103(2)$ & S2 Si2 & $2.103(2)$ \\
S1 C37 & $1.810(7)$ & S2 C74 & $1.793(8)$ \\
Si1 O1 & $1.613(4)$ & Si2 O4 & $1.600(4)$ \\
Si1 O2 & $1.609(4)$ & Si2 O5 & $1.611(4)$ \\
Si1 O3 & $1.618(4)$ & Si2 O6 & $1.607(4)$ \\
Angle & {$\left[{ }^{\circ}\right]$} & Angle & {$\left[{ }^{\circ}\right]$} \\
C37 S1 Si1 & $106.5(3)$ & C74 S2 Si2 & $106.7(3)$ \\
S1 Si1 O1 & $101.97(14)$ & S2 Si2 O4 & $114.80(17)$ \\
S1 Si1 O2 & $115.43(16)$ & S2 Si2 O5 & $101.78(16)$ \\
S1 Si1 O3 & $112.25(15)$ & S2 Si2 O6 & $112.09(15)$ \\
\hline
\end{tabular}

14]). The elements of chirality in the molecule of tris(2,6diisopropylphenoxy)silanethiol (TDST) are shown in Fig. 2. The ring $\mathrm{C} 1-\mathrm{C} 6$ is involved in the intramolecular $\mathrm{SH}-\pi$ interaction as described earlier [4, 15]. In 1 the conformations of the phenyl rings are similar to that for TDST; the phenyl rings are oriented in a propeller fashion with dihedral angles measured with respect to the $\mathrm{C} 1-\mathrm{C} 13-\mathrm{C} 25$ plane (or $\mathrm{C} 38-\mathrm{C} 50-\mathrm{C} 62$ plane for the other molecule in the independent part): (C25-C30) 7.50, (C1-C6) 67.05, (C38C43) 84.21, (C62-C67) 7.05, (C50-C55) 66.19, (C38-C43) $84.29 \mathrm{deg}$.

The molecular structures of aryloxysilanethiols were solved and refined in a monoclinic cells with one molecule of silanethiol - one of the two enantiomers - defining the independent unit $[4,12]$. The other enantiomer present in those racemic crystals was created by a set of appropriate symmetry operations on the first one. Compound $\mathbf{1}$ definitely crystallized in triclinic space group with two independent molecules (being the two enantiomers) constituting the unit cell. We repeated the measurement several times and we tried to solve the structure in higher symmetry but each time we were unsuccessful. In our opinion the major reason lies in the conformation of S-methyl group which is differently rotated in these two enantiomers. Two independent molecules of $\mathbf{1}$ are $\mathrm{P}$ and $\mathrm{M}$ enantiomers with similar (i.e. differing not more than $6(\sigma))$ but all $(+)$ or all (-) S-Si$\mathrm{O}-\mathrm{C}$ torsion angles. In our opinion the differences between $\mathrm{P}$ and $\mathrm{M}$ molecules manifest mainly in the conformation of Smethyl group, which adopts two different orientations with regard to the interacting ring.

Gust and Mislow [13] considered various flip mechanisms for the formation of two different enantiomers in case of helical triphenyl $\mathrm{Ar}_{3} \mathrm{ZX}$ compounds. We have followed similar mechanism for $\mathbf{1}$ by semi-empirical calculations with the assumption that the potential energy hypersurface of 1 contain two minima (transition Compounds TC1 and TC2) and three saddle points (Transition States TS1, TS2 and TS3) on the reaction pathway from P to M 
Fig. 3 The isomerisation pathway for $\mathbf{1}$ showing the relative energies of all involved species. Energy of $\mathrm{P}$ isomer of $\mathbf{1}$ is assigned the value of 0 $\mathrm{kcal} / \mathrm{mol}$. All molecules shown along Si-S bond. P to TC1 conversion involves the flip of the phenyl ring attached to $\mathrm{O} 1$. TC1 to TC2 involves the flip of phenyl ring attached to $\mathrm{O} 2$. The final change involves the movement of S-methyl group and undergoes practically without activation energy

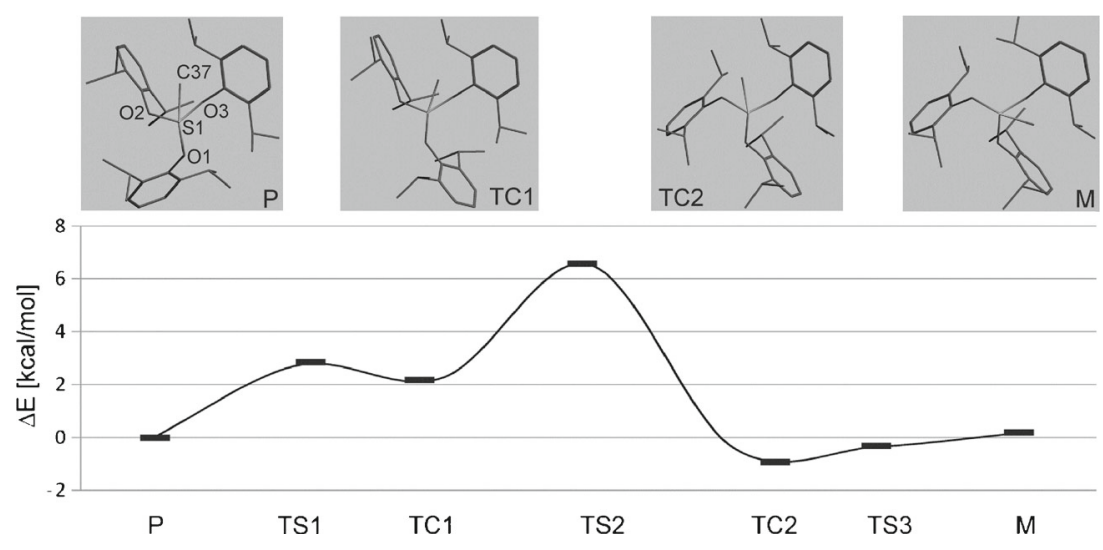

configuration as shown in Fig. 3. A saddle point with one negative eigenvalue of the force matrix corresponds to a transition state on the reaction pathway for a chemical reaction of changing enantiomeric form. Activation energy, i.e., the energy of the transition state structure relative to reactants, can be observed experimentally. However, the only way that the geometries of transition state structures can be evaluated is from theory. Transition state search algorithms rather climb up the potential energy surface, unlike geometry optimization routines where an energy minimum is searched for. The characterization of even a simple reaction potential surface may result in location of more than one transition state structure, and is likely to require many more individual calculations than are necessary to obtain equilibrium geometries for either reactant or product. For this reason the semi-empirical RM1 method of estimation of transition state energy has been chosen (see experimental).

The calculated barriers presented in Fig. 3 reach up to $6 \mathrm{kcal} / \mathrm{mol}$ thus the interconversion of $\mathrm{P}$ into $\mathrm{M}$ in solution may be significantly slowed down. On the other hand it must be remembered that for alkoxysilyl compounds racemization may as well proceed via nucleophilic substitution and the exchange of alkoxy substituents. Silicon - oxygen bond has approximately $50 \%$ ionic character and relatively easily forms pentacoordinated or hexacoordinated silicon species in the transition state of the substitution reaction [16]. The Si-O bonds in aryloxysilanethiols and in $\mathbf{1}$ are likewise strongly polarized as illustrated by potential maps visualized in Fig. 4. In order to show the regions of relatively positive and negative charges within the molecule both compounds have been mapped at 0.03 isodensity surface. It would be probably difficult to preserve the enantiomeric purity in solution of these or similar alkoxysilyl compounds but the isolation of an optically active crystal of the compound such as TDST or $\mathbf{1}$ would be possible and would require the application of a chiral additive that would force the crystallization of a particular enantiomer from the racemic solution (eg. [17]).

The calculated potential maps may also explain the relative resistance of silicon-sulfur bond present in TDST and
Fig. 4 Electrostatic potential maps of TDST (upper part of the figure, $\mathbf{a}, \mathbf{b}$ ) and $\mathbf{1}$ (lower part, $\mathbf{c}, \mathbf{d})$. The potentials were mapped either at $0.03(\mathbf{a}, \mathbf{c})$ or at $0.01(\mathbf{b}, \mathbf{d})$ isodensity surface
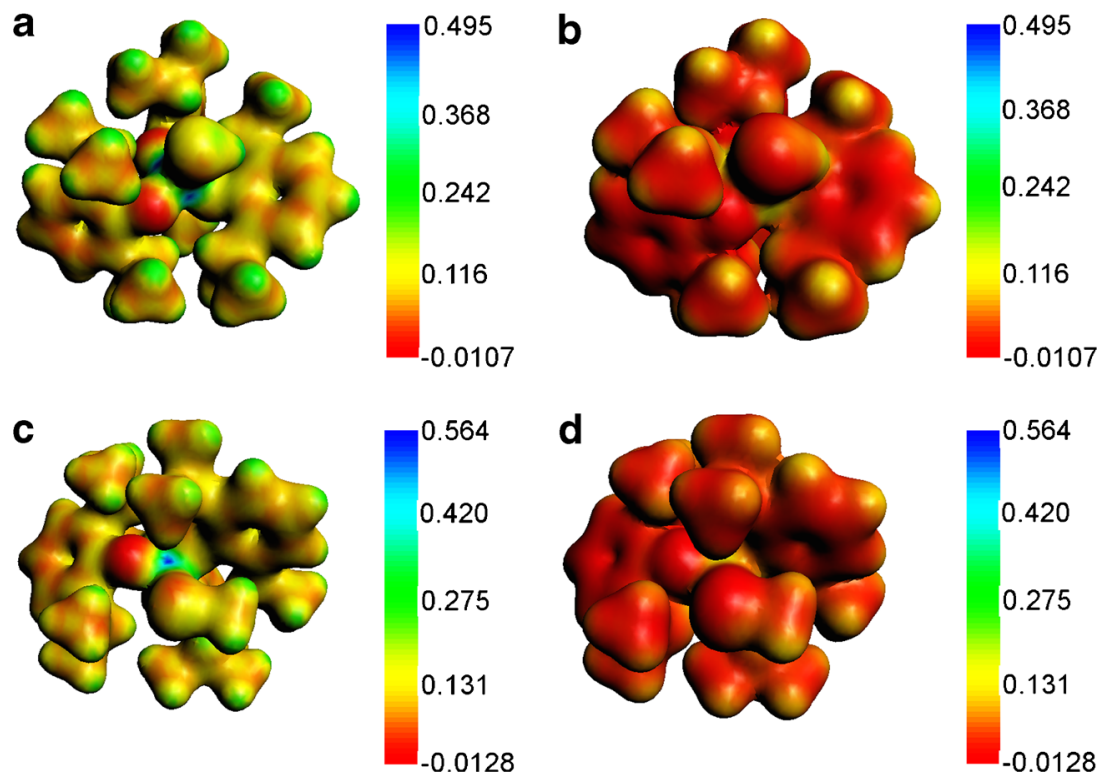
1 to the attack of nucleophiles. Mapping at 0.01 isodensity surface (Fig. 4) illustrates the strong protection against such attack, provided by hydrophobic substituents attached to oxygen atoms.

There is one more interesting feature of the studied system. Both semi-empirical and DFT calculations indicated that the energy of TC2 was the lowest of all calculated energies. It may suggest that though the crystallization of $\mathrm{P} / \mathrm{M}$ racemic mixture is energetically preferred, TC 2 could be the prevailing conformer in solution.

\section{Summary and Conclusion}

Triaryloxysilanethiols TMST and TDST and S-methyl derivative of TDST crystallize as racemic mixtures of $\mathrm{P}$ and $\mathrm{M}$ propeller-shaped enantiomers. There is probably more than one s conformation of S-methyl group in the molecule of methyl tri-(2,6-diisopropylphenoxysilyl) sulfide. The energy barrier for interconversion between the enantiomers evaluated from PM1 calculations is approximately $6 \mathrm{kcal} / \mathrm{mol}$.

Acknowledgments The studies are supported by the Polish National Science Centre grant N N204 511639

\section{References}

1. Wolf C (2008) Dynamic Stereochemistry of Chiral Compounds. Principles and Applications. The Royal Society of Chemistry, Cambridge

2. Chojnacki J, Ciborska A, Wojnowski W (2008) Acta Crystallogr C64:m240
3. Pladzyk A, Baranowska K, Gudat D, Godlewska S, Wieczerzak M, Chojnacki J, Bulman M, Januszewicz K, Dołęga A (2011) Polyhedron 30:1191

4. Dołega A, Marynowski W, Baranowska K, Śmiechowski M, Stangret J (2012) Inorg Chem 51:836

5. Sheldrick GM (2008) Acta Crystallogr A64:112

6. te Velde G, Bickelhaupt FM, van Gisbergen SJA, Fonseca Guerra C, Baerends EJ, Snijders JG, Ziegler T (2001) J Comput Chem 22:931

7. Fonseca Guerra C, Snijders JG, te Velde G, Baerends EJ (1998) Theor Chem Account 99:391

8. Baerends EJ, Ziegler T, Autschbach J, Bashford D, Bérces A, Bickelhaupt FM, Bo C, Boerrigter PM, Cavallo L, Chong DP, Deng L, Dickson RM, Ellis DE, van Faassen M, Fan L, Fischer TH, Fonseca Guerra C, Franchini M, Ghysels A, Giammona A, van Gisbergen SJA, Götz AW, Groeneveld JA, Gritsenko OV, Grüning M, Gusarov S, Harris FE, van den Hoek P, Jacob CR, Jacobsen H, Jensen L, Kaminski JW, van Kessel G, Kootstra F, Kovalenko A, Krykunov MV, van Lenthe E, McCormack DA, Michalak A, Mitoraj M, Morton SM, Neugebauer J, Nicu VP, Noodleman L, Osinga VP, Patchkovskii S, Pavanello M, Philipsen PHT, Post D, Pye CC, Ravenek W, Rodríguez JI, Ros P, Schipper PRT, Schreckenbach G, Seldenthuis JS, Seth M, Snijders JG, Solà M, Swart M, Swerhone D, te Velde G, Vernooijs P, Versluis L, Visscher L, Visser O, Wang F, Wesolowski TA, van Wezenbeek EM, Wiesenekker G, Wolff SK, Woo TK, Yakovlev AL ADF2013, SCM,Theoretical Chemistry, Vrije Universiteit, Amsterdam, The Netherlands. http://www.scm.com

9. Rocha GB, Freire RO, Simas AM, Stewart JJP (2006) J Comput Chem 27:1101

10. Baker J (1986) J. Comput. Chem 7:385

11. Piękoś R, Wojnowski W (1962) Z Anorg Allg Chem 318:212

12. Marynowski W, Klucznik T, Baranowska K, Dołega A, Wojnowski W (2010) Z Anorg Allg Chem 636:685

13. Gust D, Mislow K (1973) J Am Chem Soc 95:1535

14. Andreetti GD, Bocelli G, Calestani G, Sgarabotto P (1984) J Organomet Chem 273:31

15. Jabłońska A, Ponikiewski Ł, Ejsmont K, Herman A, Dołega A (2013) J Mol Struct 1054-1055:359

16. Bassindale AR, Lau JC-Y, Taylor PG (1995) J Organomet Chem 499:137

17. Olszewska T, Sikorski A, Herman A, Połoński T (2013) Org Biomol Chem 11:7522 